\section{PubMed inclusion: Clinical and Experimental Emergency Medicine joins the club}

\author{
Adam J Singer \\ Department of Emergency Medicine, Stony Brook University, Stony Brook, NY, USA
}

The National Library of Medicine (NLM) was established to help the advancement of medical and related sciences by disseminating scientific information to the scientific community. To achieve this goal the NLM attempts to aggregate and maintain appropriate library materials in what is known as PubMed Central (PMC). At the end of 2015 the NLM included approximately 28 million items. In order to be included in the library, a journal should demonstrate quality editorial work, including features that contribute to the objectivity, credibility, and quality of its content. The quality of the sponsoring organization is also considered in the decision to include a new journal. In general, NLM only considers an application from a journal that has at least a two-year history of quality scholarly publishing in the life sciences, and a minimum of 25 peer reviewed articles. While exact data on the acceptance rates and time from submission to acceptance are unknown, many journals are turned down and when accepted, it usually takes one to two years from submission to inclusion in PMC.

I am therefore extremely pleased to announce that the NLM approved our submission in October 2016 and Clinical and Experimental Emergency Medicine (CEEM) is now included in PMC. This achievement is especially remarkable since we were approved less than 3 years after journal inauguration and after our very first attempt. This is a credit not only to our distinguished editorial board but also to our many contributors and reviewers from Korea and across the globe. It is also a testament to the high quality of the Korean Society for Emergency Medicine, who sponsors our journal. I would especially like to thank Dr. Kyuseok Kim and Dr. Won Chul Cha as well as our managing secretary, Guyoung Choi, whose efforts were crucial to the success of our submission.

As a reminder, CEEM first began receiving submissions in June 2014 and the first issue was published in September of the same year. Our application to be included in PMC was submitted in August 2015 and as of October 25, 2016 CEEM is now indexed in PMC. Over the last 3 years we have received 253 submissions of which 147 (58.1\%) have been accepted and 115 (45.5\%) published. The majority of submissions have come from Korea (75\%), with the remainder coming from multiple countries including the US, Turkey, Hong-Kong, Israel, Belgium, Iran, and Singapore.

Given our recent success we anticipate a significant rise in both the quantity and quality of submissions to our journal in the years to come. Please continue to submit your work to our Journal and help spread the word to our colleagues in Korea and across the world that CEEM has joined the club and that we are now part of PMC.

Let us all celebrate our success.

\section{CONFLICT OF INTEREST}

No potential conflict of interest relevant to this article was reported.
elSSN: 2383-4625

Received: 18 February 2017

Revised: 20 February 2017

Accepted: 20 February 2017

Correspondence to: Adam J Singer Department of Emergency Medicine, Stony Brook University, HSC-L4-080, Stony Brook, NY 11794, USA

E-mail: adam.singer@stonybrook.edu

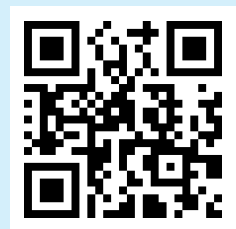

How to cite this article:

Singer AJ. PubMed inclusion: Clinical and Experimental Emergency Medicine joins the club. Clin Exp Emerg Med 2017;4(1):1-1

This is an Open Access article distributed under the terms of the Creative Commons Attribution Non-Commercial License (http:// creativecommons.org/licenses/by-nc/4.0/). 